\title{
The Pleasure of Research, Helsinki: Finnish Academy of Fine Arts by Slager, H. (2012)
}

\section{Barbara Bolt}

Faculty of the VCA and MCM University of Melbourne,Australia email: bbolt@unimelb.edu.au

What can you expect of a book called The Pleasure of Research? There are two key words in the title of the book that need to be unpacked before we can begin the project of assessing the value of this book - pleasure and research. The origin of the "pleasure" comes from the old French word "plaisir" to please. Add the English suffix, "-ure", which gives an inflection that implies action. It is pleasing to do research: What is then pleas-ure in doing research?

The word research derives from the late sixteenth century French: recerche (noun) recercher (verb). The word consists of two elements, re-, which expresses an intensive force and cerchier, 'to search.' It is both a noun and a verb: We do research and we research.However there is another sense of the "re" of re-search that needs to be considered. "Re-" is the prefix of the word "search." "Re" means "again," "again and again" and implies a withdrawal or backward motion. It is a repetitive action that returns to a previous state and repeats. However, our common sense understanding tells us that research doesn't offer us the same again, but rather something "new". This is confirmed by all the policy documents and literature around research. The Australian government, for example, defines research as:

the creation of new knowledge and/or the use of existing knowledge in a new and creative way so as to generate new concepts, methodologies and understandings. This could include synthesis and analysis of previous research to the extent that it is new and creative. (ARC, 2008: 1)

Research is not a repetition of the same. If we consider the two different nuances of "re-" together, we may understand the "re-" of research to consist of an intensive force and repetition. We return again and again, but through the intensivity of this "search", we are taken somewhere else. Here we begin to talk about the "new" of research, as the difference that emerges from the intensive force of repetition.Thus, we could say at the outset that the pleasure of research is the movement in thought, word and deed that 
occurs through the back and forward of re-search.

In The Pleasure of ResearchHenkSlagerdoes not set out tochronicle the whole field of research, a field that has been dominated by scientific research. Rather, hefocuses specifically on an emerging type of research and a new type of researcher;artistic research and the artistic researcher. Through this focus, the book aims to position artistic research as an autonomous 'experimental method and an implicated form of artistic thought', and it is the artistic researcher who gains intellectual pleasure through this process. ${ }^{1}$

At first, I doubted whether it was appropriate to do a review of this "European" take on research, with its references to the "Bologna" process, in the context of the development of artistic research in South East Asia. ${ }^{2}$ However, while the book is written from the viewpoint of a European artistic researcher, the book offers the reader and the budding artistic researcherssome "kernels" of ideas or concepts and asks them to use these as a provocation to commit research. Further it directs the reader to artistic researchers and artistic projects from across the globe to demonstrate how the concepts work in practice.

The Pleasure of Research is not the definitive tome on artistic research and researchers, nor is it an end in itself that sets out the state of this emerging research field. Rather, it is a thin pocket size book, something like a guidebook that one carries around when one goes to a new place and is looking for places to stay, the best restaurants to eat at, or the most important landmarks to visit. Or else, one could see it as some sort of a newfangled dictionary; it offers us words, concepts and examples of artistic projectsthat may be useful in our journey into this emerging world. It asks us to set off on our own unique path of discovery rather than offering us the rules of the game.

In Chapter 2, Slager introduces us to the idea of "experimental aesthetics" and the laboratorium. He explains that 'a shift has emerged from art practices focusing on end products to art practices dealing with experimental, laboratory-style environments and researching novel forms of knowledge and experience' (Slager ,2012: 22). To exemplify this shift, he draws on Laboratorium, an interdisciplinary project conducted by Hans-Ulrich Obrist and Barbara Vanderlinden in 1999. Laboratorium investigated the possibilities, congruencies and antagonisms between the scientific laboratory and the artist's studio. The project, which involved artists, curators, writers and scientists addressed the question: What is the "meaning and role of "the experiment" and to what extent is it of importance for knowledge production that the experiments taking place in the studio or the laboratory ultimately are made known demonstrably to the public?'(Slager, 2012: 22).

In some senses the experimental space of artistic research, the laboratorium, may be seen to have a kinship with the scientific laboratory. Science has its laboratories, its

1 See thedust jacket blurb of Slager, H. (2012) The Pleasure of Research, Helsinki: Finnish Academy of Fine Arts.

2 The Bologna Framework involved the structural reform of Higher Education in Europe. In the arts it has resulted in a shift from the art academy to modular based higher education programs and the introduction of doctoral programs. See Ute Meta Bauer's publication Education, Information, Entertainment: New Approaches in Higher Artistic Education (2001). 
strict laboratory practices, controlled experiments, methods and data analysis, its modes of dissemination (the peer reviewed journal article) and its audience. Scientific experiments also have requirement that the method is explicit and can be replicated in order to validate the results of an experiment. Art also has its audiences. However, as Slager points out, drawing on the Duchampian idea that every work of art should be approached as if it is the first work of art, the studio is a 'laboratory without protocol' (Slager 2012: 22). ${ }^{3}$

In a world where we are told to "listen to what the science says", what does the notion of a laboratory without protocols offer us? Philosopher of science, Bruno Latour, who was one of the "scientists" to take part in Laboratorium, suggests a critical distinction between science and research:

Science is certainty, Research is uncertainty. Science is supposed to be cold, straight and detached; Research is warm, involving and risky. Science put an end to the vagaries of human disputes; Research fuels controversies by more controversies. Science produces objectivity by escaping as much as possible from the shackles of ideology, passions and emotions; Research feeds on all those as so much handles to render familiar new objects of enquiry. (Latour quoted in Slager 2012: 23) ${ }^{4}$

Where we have come to equate science as the model of research par excellence, Slager, draws from Latour to argue that the character of a model of research emerges from "practice" is central to the "spirit" of research: emergent, context-specific, particular, multiple and responsive. Through each of the nine chapters in this handbook, Slager sets himself the task of teasing out and teasing us with the possibilities that these "qualities" in artistic research enable. This, is for Slager, the pleasure of research and why Estelle Barrett has argued that artistic research constitutes a new paradigm of research or "successor science" (Barrett 2014: 7).

\section{REFERENCES}

Australia Research Council (ARC). (2008). 'ERA indicator descriptors', December2008, available online at: www.arc.gov.au/pdf/ERA Indicator Descriptors.pdf [accessed on October 2009].

Bauer, U. (2001). Education, Information, Entertainment: New Approaches in Higher Artistic, Vienna:Edition Selene.

Barrett, E. (2014). 'Introduction: Extending the Field: Invention, Application and Innovation in Creative Arts Enquiry' in Material Inventions: Applying Creative Arts Research, (eds) E. Barrett and B. Bolt, London: I.B. Tauris.

Bolt, B. (2011). Heidegger Reframed: Interpreting Key Thinkers For the Arts, London: I.B. Tauris.

Feyerabend P. (1978) Against Method: Outline of an Anarchistic Theory of Knowledge, London: Humanities Press.

Latour, B. (1998) 'From the World of Science to that of Research"' Science, Volume 280, Number 5361, Issue of 10 Apr 1998, pp. 208-209.

3 See Paul Feyerabend'sAgainst Method: Outline of an Anarchistic Theory of Knowledge (1978). See also 'Art as Research' in Barbara Bolt'sHeidegger Reframed: Interpreting Key Thinkers For the Arts (2011),for a discussion that distinguishes between scientific research and artistic research.

4 See Bruno Latour 'From the World of Science to that of Research"' Science, Volume 280, Number 5361, Issue of 10 Apr 1998, pp. 208-209. 